\title{
Neural mechanisms of criminal decision making in adolescence:
}

The roles of executive functioning and empathy

\section{Oxford handbook of offender decision making}

Eduard T. Klapwijki,2, Wouter van den Bos $^{3}$, Berna Güroğluª

${ }^{1}$ Department of Child and Adolescent Psychiatry, Curium - Leiden University Medical Center, Leiden, The Netherlands

${ }^{2}$ Leiden Institute for Brain and Cognition, Leiden, the Netherlands

${ }^{3}$ Center for Adaptive Rationality (ARC), Max-Planck-Institute for Human Development, Berlin, Germany

${ }^{4}$ Institute of Psychology, Leiden University, Leiden, Netherlands

Acknowledgements: The authors would like to thank Geert-Jan Will for helpful comments on an earlier version of this chapter. 


\begin{abstract}
Adolescence is a time of change in which there is an increase and peak in criminal behavior. In the current chapter we discuss the neurocognitive mechanisms underlying criminal decision making in adolescents. First we provide a brief overview of the neural basis of decision making in typically developing adolescents. Second, we discuss studies that examine decision making processes in delinquent and antisocial adolescents compared to their typically developing peers. We focus on executive functioning and empathy, and conclude that delinquent and antisocial adolescents mainly display affective deficits. This is manifested in risky and impulsive decisions and in impaired sensitivity to the distress and perspectives of other people. Finally, we argue that future research on criminal decision making in adolescence could benefit from focusing on subgroups of offenders and from including environmental factors such as peer influence in experimental designs.
\end{abstract}


During adolescence the prevalence of criminal behavior tends to increase, to peak in late adolescence, and then to decrease in adulthood, a phenomenon referred to as the 'age-crime curve' (see Figure 1) (Hirschi \& Gottfredson, 1983; Loeber \& Farrington, 2014). It is possible that criminal behavior mostly results from a combination of different factors (e.g., genetic, environmental) that influence decision making processes (Moffitt, 2005). For example, biological dispositions may place certain children at risk for antisocial behavior but this risk might increase or decrease as a result of life experiences, particularly in interactions with parents and peers (Dodge \& Pettit, 2003). In the current chapter we will focus on the underlying neurocognitive mechanisms in criminal decision making in adolescents. Understanding the decision making processes and the possible differences herein between adolescents and adults may be crucial for gaining insight in the 'age-crime curve'. In the first part we will provide a general overview of the neural basis of decision making in typically developing adolescents, and in the second part we will discuss studies that examine these processes in delinquent and antisocial adolescents.

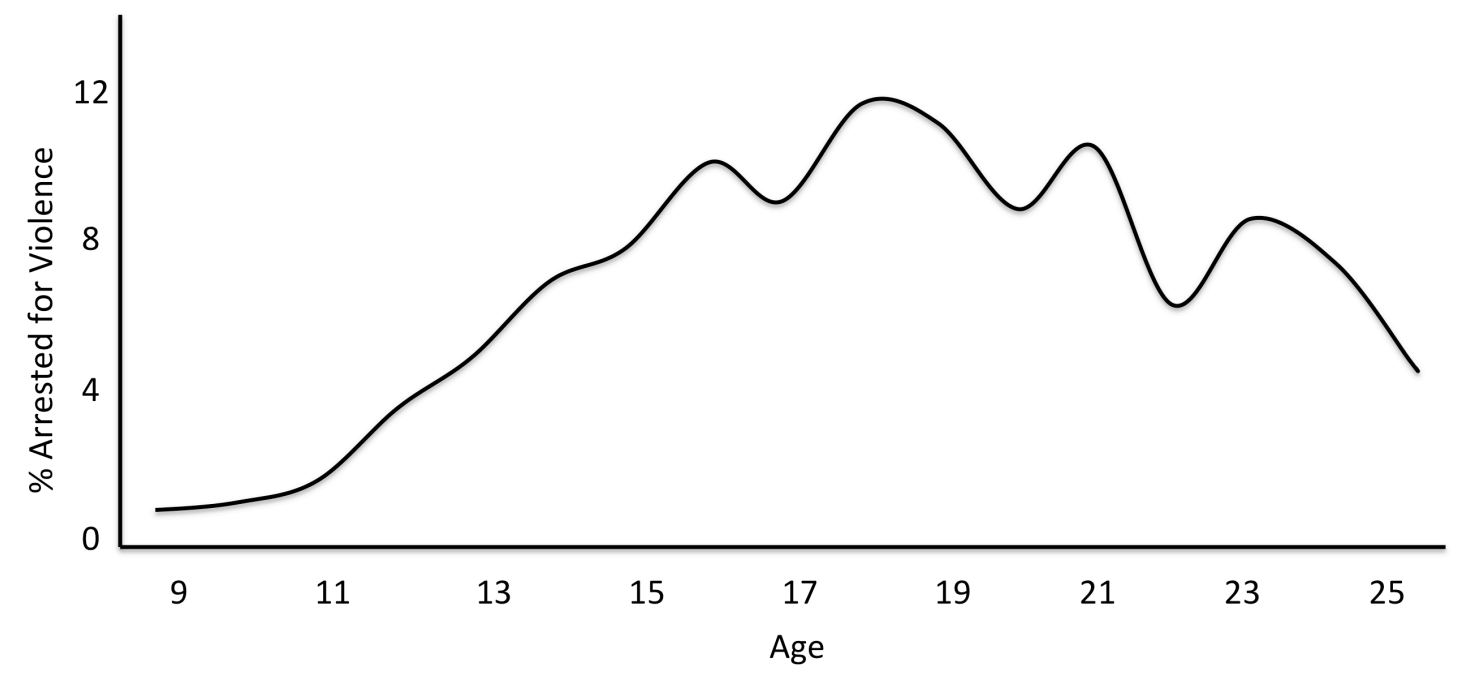

Figure 1. Age crime curve, based on longitudinal data from the Pittsburgh Youth Study and using self-reported delinquency and official records of offending. Reprinted with permission from Loeber and Farrington (2014). 
Several cognitive processes may be involved in decisions that result in a person breaking the law (i.e., criminal decision making). We will focus on two of these processes and their underlying neural circuitry; executive functioning and empathic skills. Executive functioning is an umbrella term that refers to domain general regulatory and control functions, including inhibition, self-regulation, planning and organization. Poor executive functioning involves an inability to control behavior and may lead to increased impulsive risk taking and difficulties in considering the future implications of one's acts. Indeed, poorer executive functioning is generally observed in antisocial compared to typically developing individuals (Morgan \& Lilienfeld, 2000). Hence, juveniles with executive functioning deficits are at increased risk of criminal behavior, especially when their environment provokes or fosters such behaviors (Moffitt \& Henry, 1989). When criminal acts directly involve victims, offender decision making might be influenced by a lack of empathic feelings. Empathy is the ability to share and understand the feelings of others and is usually divided into affective (e.g., shared affect, emotional resonance) and cognitive (e.g., emotion recognition, perspective-taking, self-other distinction) aspects (Decety \& Jackson, 2004; Shamay-Tsoory et al., 2009). Realizing and feeling that the victim will suffer is thought to motivate individuals to inhibit harmful behavior. Many studies have indeed found a negative relationship between empathy and aggression (Lovett \& Sheffield, 2007). Together, research in the domains of executive functioning and empathy provide insight in how adolescents make decisions that have detrimental consequences for the self (e.g., problems in considering the implications of being arrested) and for others (e.g., lack of empathy for suffering victims of crime).

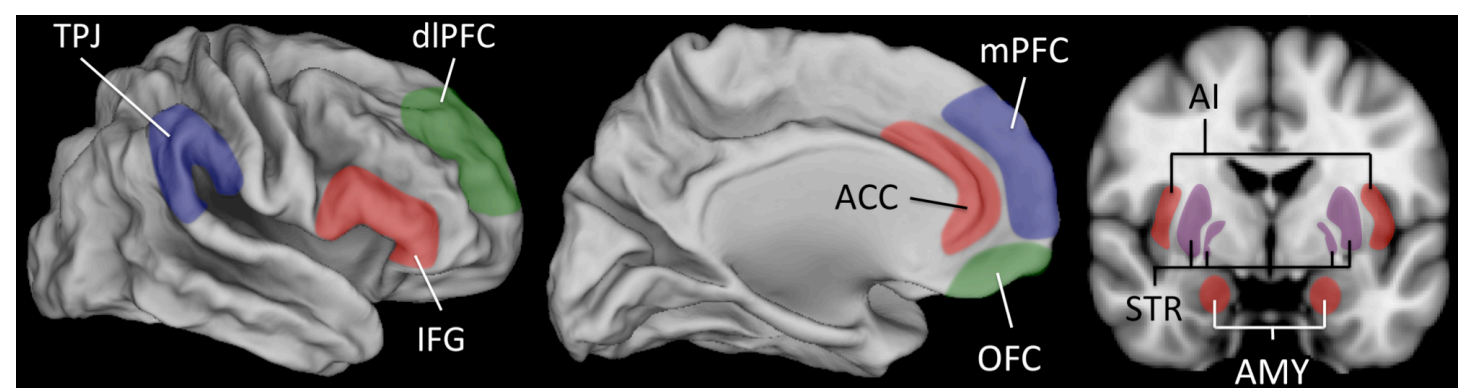

Figure 2. Schematic representation of brain networks involved in affective empathy (red), cognitive empathy / mentalizing (blue) and regulation (green). TPJ = temporoparietal junction; 
$\mathrm{IFG}=$ inferior frontal gyrus; $\mathrm{dlPFC}=$ dorsolateral prefrontal cortex; $\mathrm{ACC}=$ anterior cingulate cortex; $\mathrm{OFC}=$ orbitofrontal cortex; $\mathrm{mPFC}=$ medial prefrontal cortex; $\mathrm{STR}=$ striatum; $\mathrm{AI}=$ anterior insula; $\mathrm{AMY}=$ amygdalae.

\section{Development of brain networks in adolescence}

One of the plausible explanations for the increase in offending during adolescence is the increase in risk taking and impulsive behavior in this age period (Steinberg, 2008). In general, decision making by adolescents involves more risky and impulsive choices in comparison with adults (Blakemore \& Robbins, 2012). This developmental pattern is often associated with the finding that executive functioning, which relies heavily on frontal lobe functioning, is still improving during this period (Blakemore \& Choudhury, 2006). Several landmark studies have shown prolonged brain development during adolescence, especially in the frontal lobes (Giedd et al., 1999; Gogtay et al., 2004). Furthermore, experimental studies have found increasing activation of the dorsolateral prefrontal cortex (dlPFC; see Figure 2 for an overview of brain regions discussed in the current chapter) from childhood towards adulthood, which has been linked to increasing regulation and control with age (Güroğlu et al., 2011; Luna et al., 2001; Steinbeis et al., 2012; van Leijenhorst et al., 2010). Besides the gradual development of control related brain areas across adolescence, neuroimaging studies have also shown a specific adolescence related change in the affective system of subcortical areas including the amygdala and striatum (Ernst et al., 2005; Hare et al., 2008). In contrast with the prolonged developmental trajectory of the control system, the affective system seems to mature rather early in adolescence (Nelson et al., 2005). This combination of findings have inspired neurodevelopmental theories that explain risky and impulsive adolescent behavior as a result of a developmental mismatch between affective and cognitive control systems in the brain (see Figure 3) (Somerville et al., 2010; Steinberg, 2008). These theories hold that faster maturation of the affective subcortical brain areas in comparison to the slower maturation of cortical frontal areas lead to more emotionally driven and risky decisions in adolescence. This maturation mismatch suggests that the strong incentive seeking behavior typically observed in adolescence is driven by the affective 
system, while the frontal control system is not yet mature enough to properly control this increase in impulses. As a result, adolescent risk taking might be especially sensitive to 'hot' contexts in which emotions play a role, whereas adolescents might show no increased risk taking in 'cold' situations compared to adults (Crone \& Dahl, 2012; Figner et al., 2009).

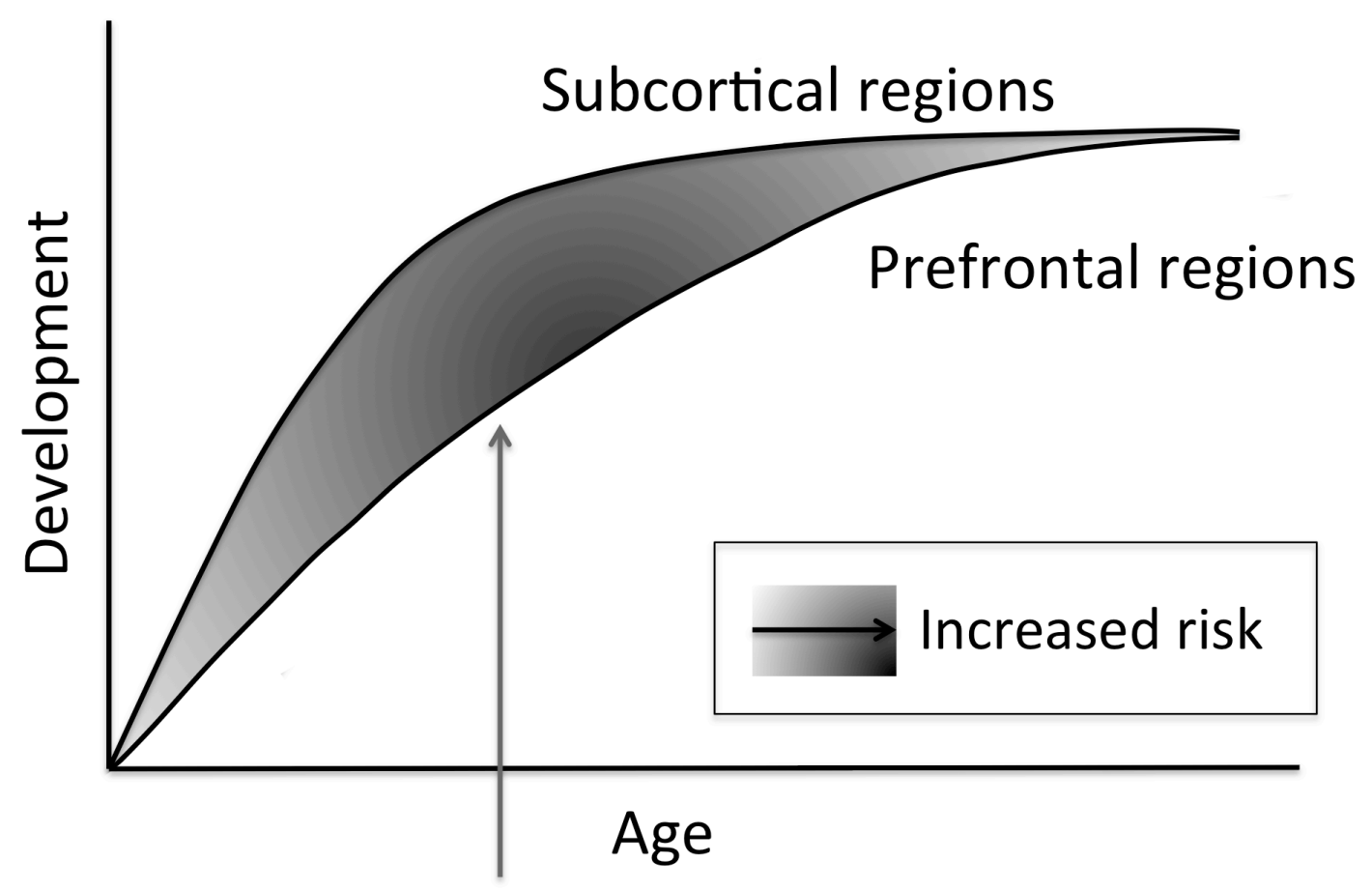

Adolescence

Figure 3. Schematic representation of the developmental mismatch model. Subcortical regions such as the amygdala and ventrial striatum (top line) mature earlier compared to prefrontal cortical regions (bottom line), leading to more emotionally driven behavior during adolescence. Reprinted with permission from Somerville et al. (2010).

Besides the changes in the affective and control systems, adolescence is moreover characterized by a process of social reorientation marked by an increased focus on peer relationships (Steinberg \& Morris, 2001). These changes in social behavior are also reflected in an improvement in taking the perspective of others during adolescence (Dumontheil et al., 2010; Güroğlu et al., 2009; Vetter et al., 2013). Neuroimaging studies have focused on understanding the neural underpinnings of these social changes by studying specific social processes such as affective and cognitive empathy (Burnett et al., 2011; Crone \& 
Dahl, 2012). Affective empathy (i.e., sharing other's emotions) is often studied using experimental paradigms in which participants observe others in pain. The rationale behind this method is that vicariously experiencing the pain of others partly activates the neural networks involved in feeling pain ourselves (Singer \& Lamm, 2009). From childhood on, in typically developing populations a network comprising the anterior insula and anterior cingulate cortex (ACC) is activated when experiencing pain firsthand as well as when observing someone else in pain (Bernhardt \& Singer, 2012; Decety et al., 2008). Other brain regions involved in empathy for pain, such as the amygdala, show a decrease in activation from childhood to adulthood, suggesting a reduction in arousal caused by other's distress with increasing age (Decety \& Michalska, 2010; Guyer et al., 2008). Possibly this reduction in spontaneous arousal or resonance with the feelings of others might be related to or resulting from increased regulation of emotions. This notion is supported by evidence showing an increase in activation in prefrontal regions involved in cognitive control and affect regulation, such as the dIPFC, with increasing age (Decety \& Michalska, 2010). These findings suggest that across adolescence individuals get better at regulating emotions caused by seeing others in pain. According to some theoretical models of the development of empathy this regulation is necessary to translate the personal stress caused by observing others in pain into positive action (i.e., prosocial behavior such as helping) (Decety \& Meyer, 2008; Eisenberg \& Fabes, 1990).

Cognitive empathy (i.e., attributing mental states to others) has been studied using a variety of tasks in adolescents, ranging from reflecting on other's thoughts and preferences (Burnett et al., 2009; Pfeifer et al., 2009) to strategic use of mental state information in social interaction games (Güroğlu et al., 2011; van den Bos et al., 2011). One specific example is a task used by Dumontheil et al. (2010) in which participants are instructed by a 'director' to move objects between a set of shelves. Since the director can only see the contents of some of the shelves, participants have to take into account the director's visual perspective in order to move the correct objects and ignore those objects that the director cannot see. In this task and other cognitive empathy (or mentalizing) tasks, participants are critically required to represent the mental states and perspectives of other persons (Frith \& Frith, 2003). 'Social brain 
regions' implicated in cognitive empathy are the temporoparietal junction (TPJ) and the medial prefrontal cortex (mPFC) (see Figure 2). Several studies have shown that activation in the TPJ tends to increase with age across adolescence, accompanied by an increase in perspective taking abilities (Blakemore et al., 2007; Güroğlu et al., 2011; van den Bos et al., 2011). In addition, activation in the mPFC decreases with age across adolescence, suggesting a shift in orientation from self to others (Burnett et al., 2009; Gunther Moor et al., 2011; Pfeifer et al., 2009; van den Bos et al., 2011).

Risk taking in adolescence is also influenced by the social changes during this life period. Accordingly, adolescents compared to adults are found to be more susceptible to the influence of peers on risk taking behavior. In one study, participants played a video game in which they drove a car on a road with junctions and traffic lights. In this task, more points could be earned by driving fast and without stopping, for example also by driving through yellow traffic lights, but points were lost if the car crashed by hitting another car at a road junction. It was shown that when adolescents played this game in the presence of their peers they showed an increase in risky decisions (as assessed by a higher number of car crashes) whereas children and adults did not show this increase (Gardner \& Steinberg, 2005). This study was followed up in an fMRI study that used the same experimental design where participants performed the driving task alone and with peers observing. During both conditions, adolescents compared to adults showed less activation in the lateral prefrontal cortex, a brain region important for cognitive control. During peer observation specifically, adolescents compared to adults showed greater activation in reward-related brain regions, including the ventral striatum. In addition, activity in these regions predicted subsequent risk taking (Chein et al., 2011). These findings suggest that the presence of peers increase adolescent risk taking, possibly due to the increased reward associated with risk taking in a social context.

In summary, research has demonstrated important changes in brain regions implicated in control, affect and social processes during typical adolescent development. During this life period, the affective brain areas mature relatively fast compared to the more gradual maturation of cortical frontal brain 
areas involved in control processes. This developmental mismatch between affective and control regions leads to an increase in sensation seeking in the absence of a sufficiently mature control system. In addition, the increased involvement of social brain regions with age, such as the TPJ, is associated with increased sensitivity to the perspective of others that might also heighten peer influence during adolescence. Together, these changes may underlie an increase in risk taking during adolescence, especially when emotions play a role such as in a social context with peers. This increase in risk taking might be an important factor that can explain the 'age-crime curve'. In addition, our understanding of the normative development can serve as a framework to interpret deviant developmental patterns in antisocial youth.

\subsection{Deviating patterns of development in adolescence}

The normative adolescent increase in risk taking, associated with the discrepancies between affective and cognitive systems, might partly explain why we see an increase in criminal behavior rates in adolescence. However, it does not explain the frequent and persistent antisocial behavior that is associated with disruptive behavior disorders, in particular with conduct disorder (CD). Conduct disorder is characterized by a repetitive and persistent pattern of antisocial behavior in which the basic rights of others or major age-appropriate societal norms are violated (American Psychiatric Association, 2013). Recent studies have estimated the lifetime prevalence of CD to be around $6.8 \%$ or $9.5 \%$ (Merikangas et al., 2010; Nock et al., 2006), whereas almost half of all incarcerated and detained adolescents fulfill criteria for CD, making it the most frequently occurring psychiatric disorder in this group (Colins et al., 2010). In addition, many symptoms of CD are also delinquent acts (e.g., stealing, raping, fire setting, weapon use) (Loeber et al., 2000). An important distinction has been made between a relatively infrequent form of CD that begins in childhood and persists into antisocial behavior in adulthood (early-onset CD) and a relatively common form of CD that sets on in adolescence and mostly desists thereafter (Moffitt et al., 2002). It is hypothesized that CD is related to impairments in brain regions implicated in moral cognition, emotion and executive functions, resulting in the inability to follow moral guidelines (Raine \& Yang, 2006). Indeed, 
difficulties in emotion processing have been found in CD (Herpertz et al., 2005), as well as impairments in executive functioning (Morgan \& Lilienfeld, 2000; Oosterlaan et al., 1998) that are already present in preschool children with CD symptoms (Schoemaker et al., 2012).

Another subgroup of antisocial and aggressive youths that has received increasing attention from researchers in the previous years is a group with conduct problems and high psychopathic traits. This research is mostly focused on a specific component of psychopathy, namely callous-unemotional (CU) traits (e.g., lack of guilt and empathy, callous use of others for one's own gain). Antisocial adolescents with high CU traits are thought to represent a specific group within antisocial and CD youth with a distinct neurocognitive profile characterized by low levels of fear and anxiety, blunted emotional reactivity and insensitivity to punishment (Blair, 2013; Frick et al., 2014). Moreover, it is suggested that antisocial individuals with high levels of CU traits exhibit a pattern of more severe and chronic antisocial behavior than those with low levels of these traits (Frick et al., 2005). In the current chapter, we will focus on studies of decision making in adolescent offenders recruited in forensic settings as well as studies that include antisocial adolescents with a diagnosis of CD (with high or low CU traits). In this overview, we will specifically focus on executive functioning and empathic processes that are related to the antisocial behaviors displayed by these groups.

\subsection{Executive functioning in antisocial adolescents}

Multiple studies provide converging lines of evidence that poor self control is an important risk factor for criminal behavior (Pratt \& Cullen, 2000).

Developmental neuroscience models suggest that risky behavior in adolescence results from slower maturation of cognitive control compared to affective systems in the brain. Accordingly, there is evidence that young offenders present a subgroup of adolescents with particularly poor executive functioning skills, which is associated with risky decision making. For example, adolescents aged 14 to 18 years with either early- or adolescence-onset CD completed a task in which they could make risky decisions involving gains and losses (Fairchild et al., 2009). Participants could choose one of two roulette wheels: one wheel showed 
equal chances of gaining and losing money and one wheel displayed various probabilities of gains and losses. Both CD groups exhibited more risky decision making than typically developing controls across a range of choices that varied in probability and size of the potential gains and losses. Importantly, these groups did not differ from typically developing controls in performance on the Wisconsin card sorting test, an established measure of global 'cold' (i.e., cognitive) executive functioning. This suggests that antisocial youth have specific deficits in affective and not cognitive control, because they make more risky choices in a 'hot' (i.e., affective) context independent of cognitive executive functioning deficits (Fairchild et al., 2009). In another study with a group of young offenders (aged 12 to 18 years) that used a similar roulette wheel task to measure risky choices, young offenders also made more risky decisions than typically developing controls (Syngelaki et al., 2009). In addition, young offenders gambled more in contrast to control participants just after they had received a small compared to a big win, suggesting again that offenders make more risky decisions in an affective context.

A key function implicated in reward based decision making is affect regulation. This involves regulatory processes in the orbitofrontal cortex (see Figure 2) that generate and adjust the emotional responses that are used to assess risks (Ochsner \& Gross, 2005). For example, neurological patients with damage to the orbitofrontal cortex show impaired decision making under risk, which has been argued to be the result of an inability to optimally learn from rewards and punishments (Bechara, 2004). Structural MRI studies have shown that youths with CD have reduced grey matter volume and cortical thickness in the orbitofrontal cortex, suggesting problems with affect regulation (Fairchild et al., 2011; Huebner et al., 2008; Hyatt et al., 2012). Possible differences in affect regulation might also manifest themselves in aberrant reward processing in antisocial youth. For instance, in passive avoidance tasks, in which participants learn to respond to rewarding stimuli and to refrain from responding to stimuli that generate punishment, altered neural responses in the orbitofrontal cortex in participants with CD have been shown. In such passive avoidance tasks, youth with CD show reduced activity in both the orbitofrontal cortex and caudate in response to reward and punishment outcomes (Finger et al., 2011; White et al., 
2013). Similarly, in a study in which participants had to respond to target letters only and had to ignore non-target letters in order to receive rewards, a rewardrelated dysfunction in the orbitofrontal cortex in boys with CD was found (Rubia et al., 2009).

Impulsivity and self control are often measured using a 'temporal discounting task', where temporal discounting refers to the decreasing value of rewards over time. In such a task, participants are asked to make a series of choices between an immediate small reward and a delayed reward of greater value. In one study, adolescents with CD (mean age 15.7 years) more often preferred smaller immediate rewards over larger delayed rewards than typically developing controls (White et al., 2014). This may reflect a similar discounting in real life: the immediate rewards of criminal acts (e.g., gaining money by stealing) outweigh the temporally distant consequences of crime, such as jail or a criminal record (Petry, 2002). As a result, individuals high on impulsivity and low on self control seem to be more prone to choosing immediate high rewards associated with acts of crime. Furthermore, neuroimaging studies with CD youth suggest that they exhibit reduced activation in response to future rewards and punishments in the striatum and the orbitofrontal cortex during reversal learning (Finger et al., 2008). These impairments in reward representations might also further contribute to the preference for immediate rewards seen in youth with CD (White et al., 2014). This preference might lead to a focus on the short-term gains of crime. In addition, committing the crime may then seem appealing when the risk of getting caught and the impact of the possible punishment are also discounted (and hence probably underestimated).

Taken together, antisocial youth such as offenders and individuals with CD mainly show executive functioning difficulties in affective contexts and when rewards are at stake. These alterations in decision making in affective contexts may be partly explained by structural differences as well as reduced functional activity in brain regions related to the regulation of affect and reward processing, such as the orbitofrontal cortex. The impairments in affect regulation likely lead antisocial youth to make more risky choices. In addition, a heightened preference for immediate versus long term rewards combined with impairments in predicting future rewards and punishments might make the law breaking 
choices seem much more appealing to adolescent offenders than to their typically developing peers.

\subsection{Empathy in antisocial adolescents}

Diminished empathy is one of the main characteristics of aggressive, antisocial groups such as adolescents with CD and especially those with high CU traits (Decety \& Moriguchi, 2007). It is hypothesized that impairments in affective empathy (i.e., sharing other's emotions) play a more important role than impairments in cognitive empathy (i.e., understanding other's mental states) in antisocial and delinquent populations, particularly those with high CU traits (Blair, 2005; but see van den Bos et al., 2014). This is in line with the idea that feeling an aversive emotional signal in reaction to another person in distress helps to inhibit aggressive and violent behavior (Blair, 1995; Miller \& Eisenberg, 1988). The lack of empathy that is part of high CU traits might be associated with less compassion for suffering of others, resulting in the lack of a barrier to use violence and to commit crimes that result in harm to others.

Several studies found aberrant neural responses in young offenders and adolescents with CD when they observe photographs or film clips of other persons in distress. For example, brain activation as measured with EEG showed that young offenders (aged 15-18 years) have a reduced early response to pictures of others in pain compared to controls in a specific EEG component (the frontal N120 component) that is associated with an automatic aversive reaction to negative stimuli (Cheng et al., 2012). This suggests that offenders show less arousal in response to others in distress compared to controls. Two fMRI studies that used similar photographs of other persons in pain found reduced activation in youths with CD and high CU traits (aged 10-17 years) in the anterior insulaACC 'pain network', and in other brain regions linked to empathy such as the amygdala and inferior frontal gyrus (Lockwood et al., 2013; Marsh et al., 2013). Using emotional film clips and measures of vicarious responses, such as heart rate activity, studies have shown reduced responses to other's distress in groups of CD youth with CU traits compared to typically developing controls (Anastassiou-Hadjicharalambous \& Warden, 2008; de Wied et al., 2012). Thus, 
converging lines of evidence using different techniques show that affective reactions towards others in distress are reduced in offenders and CD youth.

Another frequently used method within cognitive neuroscience to probe affective empathy is by presenting facial emotions of distress cues such as fear and sadness and assessing spontaneous neural activity to these emotional expressions. Facial expressions of emotions have a communicatory function and can serve as aversive stimuli that can potentially change the behavior of the perceiver (Blair, 2003). The amygdala is an important brain structure in processing of aversive stimuli and has been shown to be particularly sensitive to facial stimuli (Sergerie et al., 2008). Adolescents with CD and psychopathic traits show reduced amygdala responses to fearful facial expressions compared to typically developing peers (Jones et al., 2009; White et al., 2012), as well as reduced coupling between the amygdala and the orbitofrontal cortex (Marsh et al., 2008). A reduced response in the amygdala was also found when fearful faces were presented below conscious awareness (masked by neutral, calm faces) in youth with CD and high CU traits (aged 10-16 years). However, in this study an increased amygdala response was found for the CD youth with low levels of CU traits compared to those with high CU traits and to controls (Viding et al., 2012). This suggests that affective empathy deficits as displayed by reduced responses to others in distress might not be omnipresent in all CD and antisocial youth, but specific for those with high levels of CU traits. In contrast, antisocial individuals with low CU traits may show more reactive, impulsive aggression resulting from an increased sensitivity to negative emotions of others, in comparison to proactive, premeditated aggression that is associated with high CU traits (Dodge et al., 1997).

Further differences in amygdala activation between CD with low and high CU traits were highlighted in a study by Sebastian et al. (2012). In this study participants had to choose the appropriate ending of a short cartoon story that required them to understand the intentions of one story character (cognitive condition) or to infer how one story character would react to another character's emotional state (affective condition). In the affective condition, reduced activation was found in the amygdala and the anterior insula in the CD group compared to typically developing youth. In addition, a closer look at the 
amygdala activation within the CD group revealed that CU traits were negatively related to amygdala activation after controlling for the amount of CD symptoms whereas the amount of CD symptoms was positively related to amygdala activation after controlling for CU traits (Sebastian et al., 2012). This latter finding might explain the heterogeneity that is often found in affective functioning in CD. For example, one study found increased amygdala activation in a small group of boys with CD when they watched others in pain (Decety et al., 2009), whereas most aforementioned studies revealed a reduced amygdala response specifically in relation to CU traits. Other studies also found reduced amygdala activation in response to sad faces in youths with CD regardless of CU traits (Passamonti et al., 2010). Hence, recent studies suggest that especially youths with antisocial behavior and high CU traits are impaired in the affective aspects of empathy. In other words, only a part of young offenders and antisocial youth may show deficits in affective empathy.

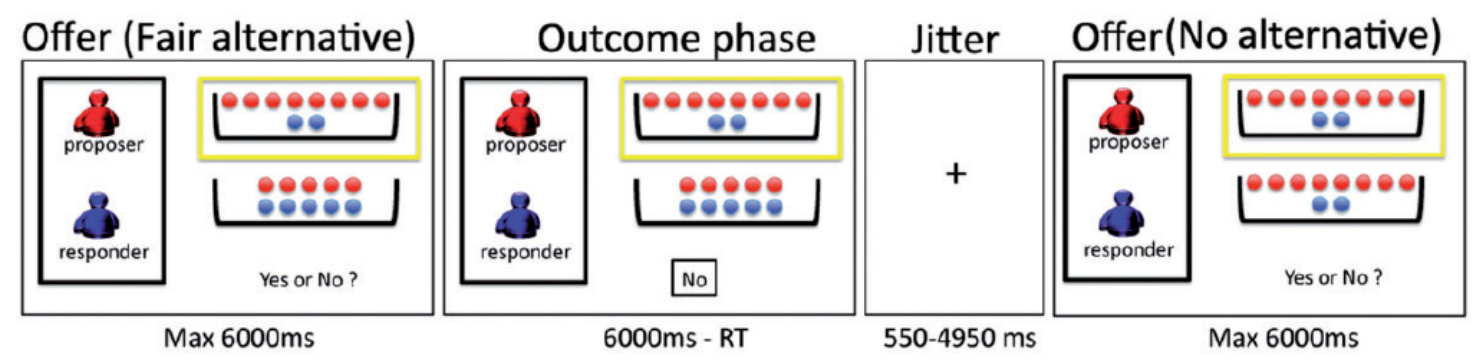

Figure 4. Trials from the mini-Ultimatum Game as used in van den Bos et al. (2014). Two offers each containing red and blue coins indicate the share for the proposer (red coins) and the responder (blue coins), the offer made by the proposer was encircled in yellow (here 8/2). The responder was given $5 \mathrm{~s}$ to select Yes or No to accept or reject the offer. Upon response, the feedback screen displayed the given response (here 'No') until $6 \mathrm{~s}$ after the start of the trial. Both the 'fair alternative' and 'no alternative' condition are displayed. Reprinted with permission from van den Bos et al. (2014).

Although most studies report problems with affective empathy in antisocial youth, the role of cognitive empathy and perspective taking in antisocial behavior is less clear. Some studies suggest that cognitive empathy does not seem to be affected in antisocial populations (Dolan \& Fullam, 2004; Jones et al., 2010; Schwenck et al., 2012), whereas other studies suggest that there are also difficulties in the cognitive domain of empathy in $\mathrm{CD}$ and in 
detained youth (Happe \& Frith, 1996; Pardini et al., 2003). For example, in our recent study (van den Bos et al., 2014), we investigated the role of perspective taking, a cognitive aspect of empathy, in the context of the mini-Ultimatum Game (mini-UG). The Ultimatum Game is an interactive economic game with two players: a proposer and a responder (see Figure 4). The game starts with the proposer making a choice on how to split a sum of money, which the responder can decide to accept or reject. When the responder accepts, both players get their share as proposed. When the responder rejects, none of the players get any money. The mini-UG is a modification of the UG and includes experimental manipulations enabling us to study intentionality considerations. Most importantly, it includes trials where the proposer had a choice to be fair (i.e., fair alternative condition; proposer has a choice between a fair and an unfair split of money) and trials where the proposer was forced to make an unfair offer (i.e., no alternative condition; proposer is given the same two unfair splits of money to choose from). A group of adolescent delinquents and a matched control group played the role of the responder while in the MRI scanner. All participants rejected unfair offers significantly less when the other player had no alternative compared to when he/she had a fair alternative. However, the delinquents more often rejected offers when the other player had no alternative than typically developing controls, suggesting they were more focused on the unfairness of the offer and less influenced by the perspective of the proposer. The neuroimaging results showed that this behavior was associated with less activation in the TPJ, a region crucial for perspective taking, but there were no differences in brain regions associated with emotional responses to unfairness (e.g., insula, ACC). This pattern of results suggests a cognitive rather than an affective impairment in situations where young delinquents are confronted with unfairness. Interestingly, the pattern of both behavior and brain activity of the delinquent group shows striking similarities with the younger children reported in a developmental study with the same task (Güroğlu et al., 2011), suggesting that there might be a developmental delay in perspective taking abilities in the adolescent offenders. However, longitudinal studies are needed to test this hypothesis in order to better characterize possible developmental differences. 
In sum, there is clear evidence for impairments in affective empathy in antisocial youth, especially in individuals with high CU traits. Neural responses in reaction to other persons in distress are diminished in the anterior insula and ACC in youth with CD, a brain network that is already involved in these processes in younger typically developing children. In addition, amygdala hypoactivation during affective empathy is mainly found in youth with high CU traits. There is also evidence for deficits in cognitive aspects of empathy such as perspective taking, although this might be especially the case during social interactions.

\section{Concluding remarks and suggestions for future research}

In this chapter we have focused on two important mechanisms of criminal decision making in juveniles, namely executive functioning and empathy. Executive functioning in young offenders and adolescents with CD is particularly weaker in affective contexts, resulting in discounting of risks and deficits in predicting future rewards. As a result, when considering the short term gains of crime both the risk of getting caught and the impact of the possible punishment is discounted (and underestimated). Therefore, committing the crime may seem much more appealing to the delinquent than to the typically developing adolescent. Additionally, difficulties in affective functioning are also apparent in studies of empathic functioning of young offenders and adolescents with CD. Reduced responses to other's distress are found in many studies, especially in adolescents with high CU traits, which might explain why some adolescents do not renounce to hurt others with threats or violence. Consequently, not only outcomes for the future self but also outcomes for others are discounted. Offending adolescents seem to combine a lack of care for what happens to others as a consequence of their criminal behavior with misperceptions about what the consequences of crime might be for themselves, and possibly a lack of care for one's own future as well. Hence, we propose that, when considering psychological mechanisms, affective deficits are one of the major processes contributing to altered decision making in delinquent and antisocial adolescents. These affective deficits manifest themselves in risky and impulsive decisions caused by problems in affect regulation and by an impaired responsiveness to 
the distress and perspective of other people, especially in seriously antisocial adolescents such as those with CD.

Another factor that is important in the context of adolescent risk taking and offending is that adolescents seem to be more sensitive to peer influence than children and adults. As studies in typically developing peers have shown, risk taking and neural processes are changed by the mere presence of peers (Chein et al., 2011; Gardner \& Steinberg, 2005). Studies have further shown that affiliation with deviant friends is strongly associated with juvenile delinquency (Heinze et al., 2004; Laird et al., 1999; Simons et al., 1994) and that adolescents are more likely to commit crimes with others than adults (Conway \& McCord, 2002; Reiss \& Farrington, 1991). Indeed, a recent longitudinal study suggests that the peak in the age-crime curve can be explained for a large part by the influence of antisocial peers (Sweeten et al., 2013). When adolescents become older and become more resistant to peer influence, engagement in antisocial behavior tends to decline (Monahan et al., 2009). Moreover, adolescents with poorer executive functioning skills such as self-regulation and greater sensitivity to reward versus punishment are more vulnerable to the influence of deviant peers on antisocial behavior (Gardner et al., 2008; Goodnight et al., 2006). It would be of great interest to initiate experimental studies to investigate peer influence specifically in antisocial and offending youth. The heightened reward related brain activity caused by the mere presence of peers in the Chein et al. (2011) study suggests that it is not necessarily the explicit encouragement of peers that influences risk taking. Using similar paradigms in young offenders or CD youth could investigate how deviant or other peers have different influences on brain and behavior and whether activation in affective and cognitive brain regions could predict peer influence on later antisocial behavior.

Previous studies have already shown that so-called 'deviancy training', in which deviant peers react more positively to each other when discussing rule breaking than more general topics, is linked to increases in violent and delinquent behavior (Dishion et al., 1997; Dishion et al., 1996). The use of neuroscience methods in combination with peer influence paradigms has the advantage that more of the underlying processes of the social influences on risk taking can be disclosed. Another advantage of such experimental studies on peer 
influence is that they could feature the use of real social interactions, by using interactive games such as we used in our recent study (van den Bos et al., 2014). This could help to evade one important limitation of many of the previous studies on empathic functioning in antisocial youth, that are mostly based on passive (viewing) and self-report tasks instead of interactions with others (Dodge, 2011). The neurocognitive mechanisms underlying real social interactions probably differ greatly from the mechanisms in merely observing others (Schilbach et al., 2013). Additionally, it has been argued that individual differences in empathy mainly become apparent when people are required to act in a situation in which someone else is harmed as opposed to merely observing such a situation (Will \& Klapwijk, 2014).

The studies that we have discussed in the current chapter included offenders recruited in forensic settings as well as participants with CD (with low and high CU traits), meaning that some of the processes we considered, such as diminished affective empathy, only hold for a particular subgroup of offenders with high CU traits. Therefore, it would be premature to conclude that all adolescent offenders show this affective deficit in executive functioning and empathy. Further comparisons of adolescent offenders and CD youths with low and high CU traits are warranted to characterize the specific pathways that lead to antisocial behavior in different groups. This reveals one of the important difficulties in the scientific study of adolescent criminal decision making: criminal behavior is conducted by a variety of individuals and disciplines such as criminology, psychology and psychiatry study different groups using different labels. Although both offenders and individuals with CD show similar behaviors, such as stealing, aggression and rule violations, offending and CD are related but not synonymous concepts. Despite these behavioral similarities, it is crucial to distinguish between subgroups of criminal adolescents since it is unlikely that the same intervention or treatment is adequate for such a diverse group (Frick \& Ellis, 1999). Recent attempts to distinguish a group of adolescents with high CU traits within CD are promising, suggesting that this group differs on a range of genetic, neurocognitive and personality characteristics from other youths with CD (for reviews see Blair, 2013; Frick et al., 2014). Crucially, neuroscience methods can serve as an important tool in establishing differences between 
subgroups and in finding possible new subgroups within CD and antisocial populations. Quantitative measures of well-defined neurocognitive processes that are associated with discrete deficits would help to provide more insight in the differences and areas of overlap between subgroups. For example, efforts have been made to apply this approach to the concepts of impulsivity and compulsivity in a range of overlapping psychiatric disorders such as attentiondeficit/hyperactivity disorder (ADHD), substance dependence and obsessivecompulsive disorder (Robbins et al., 2012). A similar approach aimed at underlying mechanisms that cross several of the current diagnostic categories (see also Insel et al., 2010) can be thought of for the concept of impulsivity in ADHD, offenders and CD, or for affective and cognitive aspects of empathy in disorders associated with social deficits such as autism and schizophrenia, in comparison to CD and offenders.

Another major challenge when focusing on the psychological mechanisms involved in adolescent criminal decision making is to integrate research on neurocognitive factors with knowledge about the influence of environmental factors. In this chapter, we chose to focus on the decision maker and on underlying neurocognitive processes of decision making. However, the role of environmental factors in decision making cannot be omitted if one wants to understand criminal behavior of adolescents. One contextual factor that we highlighted is the peer environment, which seems to be of specific importance for decision making in adolescence. Other important contextual factors of antisocial behavior that are often mentioned are the influence of parenting style and neighborhood problems (Rhee \& Waldman, 2002). It remains an empirical question whether criminal decision making is more influenced by innate neurocognitive deficits than by contextual factors that may lead to crime either by direct influences on behavior or by an indirect influence on neurocognitive abilities. Genetic twin studies and longitudinal studies have for example shown that executive functioning is very highly heritable (Friedman et al., 2008), but also that genetic influences on antisocial behavior are stronger in socioeconomically advantaged compared to disadvantaged environments (Tuvblad et al., 2006). Likewise, it is also important to take into account the possible harmful effects of incarceration during such an important 
developmental period as adolescence. Most adolescent offenders already lack certain social and executive functioning skills before being arrested; the stress of incarceration and the separation from their families and neighborhoods might not be helpful in further developing such skills.

To conclude, the neuroscience of adolescent decision making is a blossoming field and much can be learned from studies in population samples about adolescent specific behavior. However, although the prevalence of offending is significantly higher in adolescence, still only a minority of adolescents is engaged in criminal behavior. Hence, if one wants to learn more about criminal decision making in adolescents one must study groups of adolescents that show deviant behavior. Nevertheless, one should bear in mind that antisocial populations are notoriously hard to study. When including youth that is affiliated with correctional facilities they might be suspicious about the agenda of the researchers, whereas antisocial youth outside a judicial setting are hard to contact and to get and keep engaged in taking part in a study. However, we believe it is worth the effort to find ways to reach these adolescents and to design suitable paradigms aimed at elucidating the decision making processes in delinquent and antisocial youth. More fine grained knowledge about when (e.g., in affective versus cognitive contexts) and which subtypes (e.g., low versus high CU traits) of adolescent offenders make adverse decisions that result in crime may eventually help to design interventions that support adolescents at risk to stay at the right path. 


\section{References}

American Psychiatric Association. (2013). Diagnostic and statistical manual of mental disorders (5th ed.). Arlington, VA: Author.

Anastassiou-Hadjicharalambous, X., \& Warden, D. (2008). Physiologicallyindexed and self-perceived affective empathy in Conduct-Disordered children high and low on Callous-Unemotional traits. Child Psychiatry and Human Development, 39(4), 503-517. https://doi.org/10.1007/s10578008-0104-y

Bechara, A. (2004). The role of emotion in decision-making: evidence from neurological patients with orbitofrontal damage. Brain and Cognition, 55(1), 30-40. https://doi.org/10.1016/j.bandc.2003.04.001

Bernhardt, B.C., \& Singer, T. (2012). The neural basis of empathy. Annual Review of Neuroscience, 35(1), 1-23. https://doi.org/10.1146/annurev-neuro$\underline{062111-150536}$

Blair, R.J. (2013). The neurobiology of psychopathic traits in youths. Nature Reviews Neuroscience, 14(11), 786-799. https://doi.org/10.1038/nrn3577

Blair, R.J.R. (1995). A cognitive developmental approach to morality: investigating the psychopath. Cognition, 57(1), 1-29. https://doi.org/10.1016/0010-0277(95)00676-P

Blair, R.J.R. (2003). Facial expressions, their communicatory functions and neuro-cognitive substrates. Philosophical Transactions of the Royal Society B: Biological Sciences, 358(1431), 561-572. https://doi.org/10.1098/rstb.2002.1220

Blair, R.J.R. (2005). Responding to the emotions of others: Dissociating forms of empathy through the study of typical and psychiatric populations. Consciousness and Cognition, 14(4), 698-718. https://doi.org/10.1016/j.concog.2005.06.004

Blakemore, S.J., \& Choudhury, S. (2006). Development of the adolescent brain: implications for executive function and social cognition. Journal of Child Psychology and Psychiatry, 47(3-4), 296-312. https://doi.org/10.1111/j.1469-7610.2006.01611.x 
Blakemore, S.J., den Ouden, H., Choudhury, S., \& Frith, C. (2007). Adolescent development of the neural circuitry for thinking about intentions. Social Cognitive and Affective Neuroscience, 2(2), 130-139. https://doi.org/10.1093/scan/nsm009

Blakemore, S.J., \& Robbins, T.W. (2012). Decision-making in the adolescent brain. Nature Neuroscience, 15(9), 1184-1191. https://doi.org/10.1038/nn.3177

Burnett, S., Bird, G., Moll, J., Frith, C., \& Blakemore, S.J. (2009). Development during Adolescence of the Neural Processing of Social Emotion. Journal of Cognitive Neuroscience, 21(9), 1736-1750. https://doi.org/10.1162/jocn.2009.21121

Burnett, S., Sebastian, C., Cohen Kadosh, K., \& Blakemore, S.J. (2011). The social brain in adolescence: evidence from functional magnetic resonance imaging and behavioural studies. Neuroscience and Biobehavioral Reviews, 35(8), 1654-1664. https://doi.org/10.1016/j.neubiorev.2010.10.011

Chein, J., Albert, D., O'Brien, L., Uckert, K., \& Steinberg, L. (2011). Peers increase adolescent risk taking by enhancing activity in the brain's reward circuitry. Developmental Science, 14(2), F1-10. https://doi.org/10.1111/j.1467-7687.2010.01035.x

Cheng, Y., Hung, A.-Y., \& Decety, J. (2012). Dissociation between affective sharing and emotion understanding in juvenile psychopaths. Development and Psychopathology, 24(02), 623-636.

https://doi.org/10.1017/s095457941200020x

Colins, O., Vermeiren, R., Vreugdenhil, C., van den Brink, W., Doreleijers, T., \& Broekaert, E. (2010). Psychiatric disorders in detained male adolescents: a systematic literature review. Canadian Journal of Psychiatry. Revue Canadienne de Psychiatrie, 55(4), 255-263.

Conway, K.P., \& McCord, J. (2002). A longitudinal examination of the relation between co-offending with violent accomplices and violent crime. Aggressive Behavior, 28(2), 97-108. https://doi.org/10.1002/ab.90011

Crone, E.A., \& Dahl, R.E. (2012). Understanding adolescence as a period of socialaffective engagement and goal flexibility. Nature Reviews Neuroscience, 13(9), 636-650. https://doi.org/10.1038/nrn3313 
de Wied, M., van Boxtel, A., Matthys, W., \& Meeus, W. (2012). Verbal, facial and autonomic responses to empathy-eliciting film clips by disruptive male adolescents with high versus low callous-unemotional traits. Journal of Abnormal Child Psychology, 40(2), 211-223. https://doi.org/10.1007/s10802-011-9557-8

Decety, J., \& Jackson, P.L. (2004). The functional architecture of human empathy. Behavioral and Cognitive Neuroscience Reviews, 3(2), 71-100. https://doi.org/10.1177/1534582304267187

Decety, J., \& Meyer, M. (2008). From emotion resonance to empathic understanding: a social developmental neuroscience account. Development and Psychopathology, 20(4), 1053-1080. https://doi.org/10.1017/S0954579408000503

Decety, J., \& Michalska, K.J. (2010). Neurodevelopmental changes in the circuits underlying empathy and sympathy from childhood to adulthood. Dev Sci, 13(6), 886-899. https://doi.org/10.1111/j.1467-7687.2009.00940.x

Decety, J., Michalska, K.J., \& Akitsuki, Y. (2008). Who caused the pain? An fMRI investigation of empathy and intentionality in children. Neuropsychologia, 46(11), 2607-2614.

https://doi.org/10.1016/j.neuropsychologia.2008.05.026

Decety, J., Michalska, K.J., Akitsuki, Y., \& Lahey, B.B. (2009). Atypical empathic responses in adolescents with aggressive conduct disorder: a functional MRI investigation. Biological Psychology, 80(2), 203-211. https://doi.org/10.1016/j.biopsycho.2008.09.004

Decety, J., \& Moriguchi, Y. (2007). The empathic brain and its dysfunction in psychiatric populations: implications for intervention across different clinical conditions. BioPsychoSocial Medicine, 1(1), 22. https://doi.org/10.1186/1751-0759-1-22

Dishion, T.J., Eddy, J.M., Haas, E., Li, F., \& Spracklen, K. (1997). Friendships and Violent Behavior During Adolescence. Social Development, 6(2), 207-223. https://doi.org/10.1111/j.1467-9507.1997.tb00102.x

Dishion, T.J., Spracklen, K.M., Andrews, D.W., \& Patterson, G.R. (1996). Deviancy training in male adolescent friendships. Behavior Therapy, 27(3), 373390. https://doi.org/10.1016/s0005-7894(96)80023-2 
Dodge, K.A. (2011). Social information processing patterns as mediators of the interaction between genetic factors and life experiences in the development of aggressive behavior. In P. R. Shaver \& M. Mikulincer (Eds.), Human aggression and violence: Causes, manifestations, and consequences. Herzilya series on personality and social psychology. (pp. 165-185). Washington DC: American Psychological Association.

Dodge, K.A., Lochman, J.E., Harnish, J.D., Bates, J.E., \& Pettit, G.S. (1997). Reactive and proactive aggression in school children and psychiatrically impaired chronically assaultive youth. Journal of Abnormal Psychology, 106(1), 3751. https://doi.org/10.1037/0021-843x.106.1.37

Dodge, K.A., \& Pettit, G.S. (2003). A biopsychosocial model of the development of chronic conduct problems in adolescence. Developmental Psychology, 39(2), 349-371. https://doi.org/10.1037/0012-1649.39.2.349

Dolan, M., \& Fullam, R. (2004). Theory of mind and mentalizing ability in antisocial personality disorders with and without psychopathy. Psychological Medicine, 34(6), 1093-1102. https://doi.org/10.1017/s0033291704002028

Dumontheil, I., Apperly, I.A., \& Blakemore, S.J. (2010). Online usage of theory of mind continues to develop in late adolescence. Dev Sci, 13(2), 331-338. https://doi.org/10.1111/j.1467-7687.2009.00888.x

Eisenberg, N., \& Fabes, R.A. (1990). Empathy - Conceptualization, Measurement, and Relation to Prosocial Behavior. Motivation and Emotion, 14(2), 131149. https://doi.org/Doi 10.1007/Bf00991640

Ernst, M., Nelson, E.E., Jazbec, S., McClure, E.B., Monk, C.S., Leibenluft, E., Blair, J., \& Pine, D.S. (2005). Amygdala and nucleus accumbens in responses to receipt and omission of gains in adults and adolescents. Neuroimage, 25(4), 1279-1291. https://doi.org/10.1016/j.neuroimage.2004.12.038

Fairchild, G., Passamonti, L., Hurford, G., Hagan, C.C., von dem Hagen, E.A., van Goozen, S.H., Goodyer, I.M., \& Calder, A.J. (2011). Brain structure abnormalities in early-onset and adolescent-onset conduct disorder. American Journal of Psychiatry, 168(6), 624-633. https://doi.org/10.1176/appi.ajp.2010.10081184 
Fairchild, G., van Goozen, S.H., Stollery, S.J., Aitken, M.R., Savage, J., Moore, S.C., \& Goodyer, I.M. (2009). Decision making and executive function in male adolescents with early-onset or adolescence-onset conduct disorder and control subjects. Biological Psychiatry, 66(2), 162-168.

https://doi.org/10.1016/j.biopsych.2009.02.024

Figner, B., Mackinlay, R.J., Wilkening, F., \& Weber, E.U. (2009). Affective and Deliberative Processes in Risky Choice: Age Differences in Risk Taking in the Columbia Card Task. Journal of Experimental Psychology-Learning Memory and Cognition, 35(3), 709-730. https://doi.org/10.1037/a0014983

Finger, E.C., Marsh, A.A., Blair, K.S., Reid, M.E., Sims, C., Ng, P., Pine, D.S., \& Blair, R.J. (2011). Disrupted reinforcement signaling in the orbitofrontal cortex and caudate in youths with conduct disorder or oppositional defiant disorder and a high level of psychopathic traits. American Journal of Psychiatry, 168(2), 152-162.

https://doi.org/10.1176/appi.ajp.2010.10010129

Finger, E.C., Marsh, A.A., Mitchell, D.G., Reid, M.E., Sims, C., Budhani, S., Kosson, D.S., Chen, G., Towbin, K.E., Leibenluft, E., Pine, D.S., \& Blair, J.R. (2008). Abnormal ventromedial prefrontal cortex function in children with psychopathic traits during reversal learning. Archives of General Psychiatry, 65(5), 586-594. https://doi.org/10.1001/archpsyc.65.5.586

Frick, P.J., \& Ellis, M. (1999). Callous-unemotional traits and subtypes of conduct disorder. Clinical Child and Family Psychology Review, 2(3), 149-168. https://doi.org/10.1023/a:1021803005547

Frick, P.J., Ray, J.V., Thornton, L.C., \& Kahn, R.E. (2014). Can callous-unemotional traits enhance the understanding, diagnosis, and treatment of serious conduct problems in children and adolescents? A comprehensive review. Psychological Bulletin, 140(1), 1-57. https://doi.org/10.1037/a0033076

Frick, P.J., Stickle, T.R., Dandreaux, D.M., Farrell, J.M., \& Kimonis, E.R. (2005). Callous-unemotional traits in predicting the severity and stability of conduct problems and delinquency. Journal of Abnormal Child Psychology, 33(4), 471-487. https://doi.org/10.1007/s10648-005-5728-9 
Friedman, N.P., Miyake, A., Young, S.E., Defries, J.C., Corley, R.P., \& Hewitt, J.K. (2008). Individual differences in executive functions are almost entirely genetic in origin. Journal of Experimental Psychology: General, 137(2), 201225. https://doi.org/10.1037/0096-3445.137.2.201

Frith, U., \& Frith, C.D. (2003). Development and neurophysiology of mentalizing. Philosophical Transactions of the Royal Society B: Biological Sciences, 358(1431), 459-473. https://doi.org/10.1098/rstb.2002.1218

Gardner, M., \& Steinberg, L. (2005). Peer influence on risk taking, risk preference, and risky decision making in adolescence and adulthood: An experimental study. Developmental Psychology, 41(4), 625-635. https://doi.org/10.1037/0012-1649.41.4.625

Gardner, T.W., Dishion, T.J., \& Connell, A.M. (2008). Adolescent self-regulation as resilience: resistance to antisocial behavior within the deviant peer context. Journal of Abnormal Child Psychology, 36(2), 273-284. https://doi.org/10.1007/s10802-007-9176-6

Giedd, J.N., Blumenthal, J., Jeffries, N.O., Castellanos, F.X., Liu, H., Zijdenbos, A., Paus, T., Evans, A.C., \& Rapoport, J.L. (1999). Brain development during childhood and adolescence: a longitudinal MRI study. Nature Neuroscience, 2(10), 861-863. https://doi.org/10.1038/13158

Gogtay, N., Giedd, J.N., Lusk, L., Hayashi, K.M., Greenstein, D., Vaituzis, A.C., Nugent, T.F., 3rd, Herman, D.H., Clasen, L.S., Toga, A.W., Rapoport, J.L., \& Thompson, P.M. (2004). Dynamic mapping of human cortical development during childhood through early adulthood. Proceedings of the National Academy of Sciences of the United States of America, 101(21), 8174-8179. https://doi.org/10.1073/pnas.0402680101

Goodnight, J.A., Bates, J.E., Newman, J.P., Dodge, K.A., \& Pettit, G.S. (2006). The interactive influences of friend deviance and reward dominance on the development of externalizing behavior during middle adolescence. Journal of Abnormal Child Psychology, 34(5), 573-583. https://doi.org/10.1007/s10802-006-9036-9

Gunther Moor, B., Op de Macks, Z.A., Guroglu, B., Rombouts, S.A.R.B., Van der Molen, M.W., \& Crone, E.A. (2011). Neurodevelopmental changes of 
reading the mind in the eyes. Social Cognitive and Affective Neuroscience, 7(1), 44-52. https://doi.org/10.1093/scan/nsr020

Güroğlu, B., van den Bos, W., \& Crone, E.A. (2009). Fairness considerations: increasing understanding of intentionality during adolescence. Journal of Experimental Child Psychology, 104(4), 398-409. https://doi.org/10.1016/j.jecp.2009.07.002

Güroğlu, B., van den Bos, W., van Dijk, E., Rombouts, S.A., \& Crone, E.A. (2011). Dissociable brain networks involved in development of fairness considerations: understanding intentionality behind unfairness. Neuroimage, 57(2), 634-641. https://doi.org/10.1016/j.neuroimage.2011.04.032

Guyer, A.E., Monk, C.S., McClure-Tone, E.B., Nelson, E.E., Roberson-Nay, R., Adler, A.D., Fromm, S.J., Leibenluft, E., Pine, D.S., \& Ernst, M. (2008). A Developmental Examination of Amygdala Response to Facial Expressions. Journal of Cognitive Neuroscience, 20(9), 1565-1582. https://doi.org/10.1162/jocn.2008.20114

Happe, F., \& Frith, U. (1996). Theory of mind and social impairment in children with conduct disorder. British Journal of Developmental Psychology, 14, 385-398.

Hare, T.A., Tottenham, N., Galvan, A., Voss, H.U., Glover, G.H., \& Casey, B.J. (2008). Biological substrates of emotional reactivity and regulation in adolescence during an emotional go-nogo task. Biological Psychiatry, 63(10), 927-934. https://doi.org/10.1016/j.biopsych.2008.03.015

Heinze, H.J., Toro, P.A., \& Urberg, K.A. (2004). Antisocial behavior and affiliation with deviant peers. Journal of Clinical Child and Adolescent Psychology, 33(2), 336-346.

Herpertz, S.C., Mueller, B., Qunaibi, M., Lichterfeld, C., Konrad, K., \& HerpertzDahlmann, B. (2005). Response to emotional stimuli in boys with conduct disorder. American Journal of Psychiatry, 162(6), 1100-1107. https://doi.org/10.1176/appi.ajp.162.6.1100

Hirschi, T., \& Gottfredson, M. (1983). Age and the Explanation of Crime. American Journal of Sociology, 89(3), 552-584. https://doi.org/Doi 10.1086/227905 
Huebner, T., Vloet, T.D., Marx, I., Konrad, K., Fink, G.R., Herpertz, S.C., \& HerpertzDahlmann, B. (2008). Morphometric brain abnormalities in boys with conduct disorder. Journal of the American Academy of Child and Adolescent Psychiatry, 47(5), 540-547. https://doi.org/10.1097/CHI.0b013e3181676545

Hyatt, C.J., Haney-Caron, E., \& Stevens, M.C. (2012). Cortical thickness and folding deficits in conduct-disordered adolescents. Biological Psychiatry, 72(3), 207-214. https://doi.org/10.1016/j.biopsych.2011.11.017

Insel, T., Cuthbert, B., Garvey, M., Heinssen, R., Pine, D.S., Quinn, K., Sanislow, C., \& Wang, P. (2010). Research domain criteria (RDoC): toward a new classification framework for research on mental disorders. American Journal of Psychiatry, 167(7), 748-751. https://doi.org/10.1176/appi.ajp.2010.09091379

Jones, A.P., Happe, F.G., Gilbert, F., Burnett, S., \& Viding, E. (2010). Feeling, caring, knowing: different types of empathy deficit in boys with psychopathic tendencies and autism spectrum disorder. Journal of Child Psychology and Psychiatry, 51(11), 1188-1197. https://doi.org/10.1111/j.14697610.2010.02280.x

Jones, A.P., Laurens, K.R., Herba, C.M., Barker, G.J., \& Viding, E. (2009). Amygdala Hypoactivity to Fearful Faces in Boys With Conduct Problems and Callous-Unemotional Traits. American Journal of Psychiatry, 166(1), 95102. https://doi.org/10.1176/appi.ajp.2008.07071050

Laird, R.D., Pettit, G.S., Dodge, K.A., \& Bates, J.E. (1999). Best friendships, group relationships, and antisocial behavior in early adolescence. Journal of Early Adolescence, 19(4), 413-437. https://doi.org/10.1177/0272431699019004001

Lockwood, P.L., Sebastian, C.L., McCrory, E.J., Hyde, Z.H., Gu, X., De Brito, S.A., \& Viding, E. (2013). Association of callous traits with reduced neural response to others' pain in children with conduct problems. Current Biology, 23(10), 901-905. https://doi.org/10.1016/j.cub.2013.04.018 Loeber, R., Burke, J.D., Lahey, B.B., Winters, A., \& Zera, M. (2000). Oppositional defiant and conduct disorder: a review of the past 10 years, part I. Journal 
of the American Academy of Child and Adolescent Psychiatry, 39(12), 14681484. https://doi.org/10.1097/00004583-200012000-00007

Loeber, R., \& Farrington, D. (2014). Age-Crime Curve. In G. Bruinsma \& D. Weisburd (Eds.), Encyclopedia of Criminology and Criminal Justice (pp. 1218): Springer New York.

Lovett, B., \& Sheffield, R. (2007). Affective empathy deficits in aggressive children and adolescents: A critical review. Clinical Psychology Review, 27(1), 1-13. https://doi.org/10.1016/j.cpr.2006.03.003

Luna, B., Thulborn, K.R., Munoz, D.P., Merriam, E.P., Garver, K.E., Minshew, N.J., Keshavan, M.S., Genovese, C.R., Eddy, W.F., \& Sweeney, J.A. (2001). Maturation of widely distributed brain function subserves cognitive development. Neuroimage, 13(5), 786-793. https://doi.org/10.1006/nimg.2000.0743

Marsh, A.A., Finger, E.C., Fowler, K.A., Adalio, C.J., Jurkowitz, I.T., Schechter, J.C., Pine, D.S., Decety, J., \& Blair, R.J. (2013). Empathic responsiveness in amygdala and anterior cingulate cortex in youths with psychopathic traits. Journal of Child Psychology and Psychiatry, 54(8), 900-910. https://doi.org/10.1111/jcpp.12063

Marsh, A.A., Finger, E.C., Mitchell, D.G.V., Reid, M.E., Sims, C., Kosson, D.S., Towbin, K.E., Leibenluft, E., Pine, D.S., \& Blair, R.J.R. (2008). Reduced amygdala response to fearful expressions in children and adolescents with callousunemotional traits and disruptive behavior disorders. American Journal of Psychiatry, 165(6), 712-720.

https://doi.org/10.1176/appi.ajp.2007.07071145

Merikangas, K.R., He, J.P., Burstein, M., Swanson, S.A., Avenevoli, S., Cui, L.H., Benjet, C., Georgiades, K., \& Swendsen, J. (2010). Lifetime Prevalence of Mental Disorders in U.S. Adolescents: Results from the National Comorbidity Survey Replication-Adolescent Supplement (NCS-A). Journal of the American Academy of Child and Adolescent Psychiatry, 49(10), 980989. https://doi.org/10.1016/j.jaac.2010.05.017

Miller, P.A., \& Eisenberg, N. (1988). The relation of empathy to aggressive and externalizing/antisocial behavior. Psychological Bulletin, 103(3), 324-344. https://doi.org/10.1037/0033-2909.103.3.324 
Moffitt, T.E. (2005). The new look of behavioral genetics in developmental psychopathology: gene-environment interplay in antisocial behaviors. Psychological Bulletin, 131(4), 533-554. https://doi.org/10.1037/0033$\underline{2909.131 .4 .533}$

Moffitt, T.E., Caspi, A., Harrington, H., \& Milne, B.J. (2002). Males on the lifecourse-persistent and adolescence-limited antisocial pathways: Followup at age 26 years. Development and Psychopathology, 14(1), 179-207. https://doi.org/10.1017/s0954579402001104

Moffitt, T.E., \& Henry, B. (1989). Neuropsychological assessment of executive functions in self-reported delinquents. Development and Psychopathology, 1(02), 105-118. https://doi.org/doi:10.1017/S0954579400000298

Monahan, K.C., Steinberg, L., \& Cauffman, E. (2009). Affiliation With Antisocial Peers, Susceptibility to Peer Influence, and Antisocial Behavior During the Transition to Adulthood. Developmental Psychology, 45(6), 1520-1530. https://doi.org/10.1037/a0017417

Morgan, A.B., \& Lilienfeld, S.O. (2000). A meta-analytic review of the relation between antisocial behavior and neuropsychological measures of executive function. Clinical Psychology Review, 20(1), 113-136. https://doi.org/Doi 10.1016/S0272-7358(98)00096-8

Nelson, E.E., Leibenluft, E., McClure, E.B., \& Pine, D.S. (2005). The social reorientation of adolescence: a neuroscience perspective on the process and its relation to psychopathology. Psychological Medicine, 35(2), 163-174. https://doi.org/10.1017/s0033291704003915

Nock, M.K., Kazdin, A.E., Hiripi, E., \& Kessler, R.C. (2006). Prevalence, subtypes, and correlates of DSM-IV conduct disorder in the National Comorbidity Survey Replication. Psychological Medicine, 36(5), 699-710. https://doi.org/10.1017/S0033291706007082

Ochsner, K.N., \& Gross, J.J. (2005). The cognitive control of emotion. Trends in Cognitive Sciences, 9(5), 242-249. https://doi.org/10.1016/j.tics.2005.03.010

Oosterlaan, J., Logan, G.D., \& Sergeant, J.A. (1998). Response inhibition in AD/HD, $\mathrm{CD}$, comorbid $\mathrm{AD} / \mathrm{HD}+\mathrm{CD}$, anxious, and control children: a meta-analysis 
of studies with the stop task. Journal of Child Psychology and Psychiatry, 39(3), 411-425.

Pardini, D.A., Lochman, J.E., \& Frick, P.J. (2003). Callous/unemotional traits and social-cognitive processes in adjudicated youths. Journal of the American Academy of Child and Adolescent Psychiatry, 42(3), 364-371. https://doi.org/10.1097/00004583-200303000-00018

Passamonti, L., Fairchild, G., Goodyer, I.M., Hurford, G., Hagan, C.C., Rowe, J.B., \& Calder, A.J. (2010). Neural Abnormalities in Early-Onset and AdolescenceOnset Conduct Disorder. Archives of General Psychiatry, 67(7), 729-738.

Petry, N.M. (2002). Discounting of delayed rewards in substance abusers: relationship to antisocial personality disorder. Psychopharmacology, 162(4), 425-432. https://doi.org/10.1007/s00213-002-1115-1

Pfeifer, J.H., Masten, C.L., Borofsky, L.A., Dapretto, M., Fuligni, A.J., \& Lieberman, M.D. (2009). Neural Correlates of Direct and Reflected Self-Appraisals in Adolescents and Adults: When Social Perspective-Taking Informs SelfPerception. Child Development, 80(4), 1016-1038. https://doi.org/10.1111/j.1467-8624.2009.01314.x

Pratt, T.C., \& Cullen, F.T. (2000). The empirical status of Gottfredson and Hirschi's general theory of crime: A meta-analysis. Criminology, 38(3), 931-964. https://doi.org/Doi 10.1111/J.1745-9125.2000.Tb00911.X

Raine, A., \& Yang, Y. (2006). Neural foundations to moral reasoning and antisocial behavior. Social Cognitive and Affective Neuroscience, 1(3), 203213. https://doi.org/10.1093/scan/nsl033

Reiss, A.J., \& Farrington, D.P. (1991). Advancing Knowledge About Co-Offending Results from a Prospective Longitudinal Survey of London Males. Journal of Criminal Law \& Criminology, 82(2), 360-395. https://doi.org/Doi $10.2307 / 1143811$

Rhee, S.H., \& Waldman, I.D. (2002). Genetic and environmental influences on antisocial behavior: a meta-analysis of twin and adoption studies. Psychological Bulletin, 128(3), 490-529. https://doi.org/10.1037//00332909.128.3.490

Robbins, T.W., Gillan, C.M., Smith, D.G., de Wit, S., \& Ersche, K.D. (2012). Neurocognitive endophenotypes of impulsivity and compulsivity: 
towards dimensional psychiatry. Trends in Cognitive Sciences, 16(1), 8191. https://doi.org/10.1016/j.tics.2011.11.009

Rubia, K., Smith, A.B., Halari, R., Matsukura, F., Mohammad, M., Taylor, E., \& Brammer, M.J. (2009). Disorder-Specific Dissociation of Orbitofrontal Dysfunction in Boys With Pure Conduct Disorder During Reward and Ventrolateral Prefrontal Dysfunction in Boys With Pure ADHD During Sustained Attention. American Journal of Psychiatry, 166(1), 83-94. https://doi.org/10.1176/appi.ajp.2008.08020212

Schilbach, L., Timmermans, B., Reddy, V., Costall, A., Bente, G., Schlicht, T., \& Vogeley, K. (2013). Toward a second-person neuroscience. Behavioral and Brain Sciences, 36(4), 393-414. https://doi.org/10.1017/S0140525X12000660

Schoemaker, K., Bunte, T., Wiebe, S.A., Espy, K.A., Dekovic, M., \& Matthys, W. (2012). Executive function deficits in preschool children with ADHD and DBD. Journal of Child Psychology and Psychiatry, 53(2), 111-119. https://doi.org/10.1111/j.1469-7610.2011.02468.x

Schwenck, C., Mergenthaler, J., Keller, K., Zech, J., Salehi, S., Taurines, R., Romanos, M., Schecklmann, M., Schneider, W., Warnke, A., \& Freitag, C.M. (2012). Empathy in children with autism and conduct disorder: group-specific profiles and developmental aspects. Journal of Child Psychology and Psychiatry, 53(6), 651-659. https://doi.org/10.1111/j.14697610.2011.02499.x

Sebastian, C.L., McCrory, E.J.P., Cecil, C.A.M., Lockwood, P.L., De Brito, S.A., Fontaine, N.M.G., \& Viding, E. (2012). Neural Responses to Affective and Cognitive Theory of Mind in Children With Conduct Problems and Varying Levels of Callous-Unemotional Traits. Archives of General Psychiatry, 69(8), 814-822. https://doi.org/10.1001/archgenpsychiatry.2011.2070

Sergerie, K., Chochol, C., \& Armony, J.L. (2008). The role of the amygdala in emotional processing: a quantitative meta-analysis of functional neuroimaging studies. Neuroscience and Biobehavioral Reviews, 32(4), 811-830. https://doi.org/10.1016/j.neubiorev.2007.12.002 Shamay-Tsoory, S.G., Aharon-Peretz, J., \& Perry, D. (2009). Two systems for empathy: a double dissociation between emotional and cognitive 
empathy in inferior frontal gyrus versus ventromedial prefrontal lesions. Brain, 132(3), 617-627. https://doi.org/10.1093/brain/awn279

Simons, R.L., Wu, C.-I., Conger, R.D., \& Lorenz, F.O. (1994). Two Routes to

Delinquency: Differences between Early and Late Starters in the Impact of Parenting and Deviant Peers*. Criminology, 32(2), 247-276. https://doi.org/10.1111/j.1745-9125.1994.tb01154.x

Singer, T., \& Lamm, C. (2009). The social neuroscience of empathy. Annals of the New York Academy of Sciences, 1156(1), 81-96. https://doi.org/10.1111/j.1749-6632.2009.04418.x

Somerville, L.H., Jones, R.M., \& Casey, B.J. (2010). A time of change: behavioral and neural correlates of adolescent sensitivity to appetitive and aversive environmental cues. Brain and Cognition, 72(1), 124-133. https://doi.org/10.1016/j.bandc.2009.07.003

Steinbeis, N., Bernhardt, B.C., \& Singer, T. (2012). Impulse control and underlying functions of the left DLPFC mediate age-related and age-independent individual differences in strategic social behavior. Neuron, 73(5), 10401051. https://doi.org/10.1016/j.neuron.2011.12.027

Steinberg, L. (2008). A Social Neuroscience Perspective on Adolescent RiskTaking. Developmental Review, 28(1), 78-106. https://doi.org/10.1016/j.dr.2007.08.002

Steinberg, L., \& Morris, A.S. (2001). Adolescent development. Annual Review of Psychology, 52, 83-110. https://doi.org/10.1146/annurev.psych.52.1.83

Sweeten, G., Piquero, A.R., \& Steinberg, L. (2013). Age and the explanation of crime, revisited. J Youth Adolesc, 42(6), 921-938. https://doi.org/10.1007/s10964-013-9926-4

Syngelaki, E.M., Moore, S.C., Savage, J.C., Fairchild, G., \& Van Goozen, S.H.M. (2009). Executive Functioning and Risky Decision Making in Young Male Offenders. Criminal Justice and Behavior, 36(11), 1213-1227. https://doi.org/10.1177/0093854809343095

Tuvblad, C., Grann, M., \& Lichtenstein, P. (2006). Heritability for adolescent antisocial behavior differs with socioeconomic status: gene-environment interaction. Journal of Child Psychology and Psychiatry, 47(7), 734-743. https://doi.org/10.1111/j.1469-7610.2005.01552.x 
van den Bos, W., Vahl, P., Güroğlu, B., van Nunspeet, F., Colins, O., Markus, M., Rombouts, S.A., van der Wee, N., Vermeiren, R., \& Crone, E.A. (2014). Neural correlates of social decision-making in severely antisocial adolescents. Social Cognitive and Affective Neuroscience, 9(12), 20592066. https://doi.org/10.1093/scan/nsu003

van den Bos, W., van Dijk, E., Westenberg, M., Rombouts, S.A., \& Crone, E.A. (2011). Changing brains, changing perspectives: the neurocognitive development of reciprocity. Psychol Sci, 22(1), 60-70. https://doi.org/10.1177/0956797610391102

van Leijenhorst, L., Gunther Moor, B., Op de Macks, Z.A., Rombouts, S.A., Westenberg, P.M., \& Crone, E.A. (2010). Adolescent risky decision-making: neurocognitive development of reward and control regions. Neuroimage, 51(1), 345-355. https://doi.org/10.1016/j.neuroimage.2010.02.038

Vetter, N.C., Leipold, K., Kliegel, M., Phillips, L.H., \& Altgassen, M. (2013). Ongoing development of social cognition in adolescence. Child Neuropsychol, 19(6), 615-629. https://doi.org/10.1080/09297049.2012.718324

Viding, E., Sebastian, C.L., Dadds, M.R., Lockwood, P.L., Cecil, C.A.M., De Brito, S.A., \& McCrory, E.J. (2012). Amygdala Response to Preattentive Masked Fear in Children With Conduct Problems: The Role of Callous-Unemotional Traits. American Journal of Psychiatry, 169(10), 1109-1116. https://doi.org/10.1176/appi.ajp.2012.12020191

White, S.F., Clanton, R., Brislin, S.J., Meffert, H., Hwang, S., Sinclair, S., \& Blair, R.J. (2014). Reward: empirical contribution. Temporal discounting and conduct disorder in adolescents. J Pers Disord, 28(1), 5-18. https://doi.org/10.1521/pedi.2014.28.1.5

White, S.F., Marsh, A.A., Fowler, K.A., Schechter, J.C., Adalio, C., Pope, K., Sinclair, S., Pine, D.S., \& Blair, R.J.R. (2012). Reduced Amygdala Response in Youths With Disruptive Behavior Disorders and Psychopathic Traits: Decreased Emotional Response Versus Increased Top-Down Attention to Nonemotional Features. American Journal of Psychiatry, 169(7), 750-758. https://doi.org/10.1176/appi.ajp.2012.11081270

White, S.F., Pope, K., Sinclair, S., Fowler, K.A., Brislin, S.J., Williams, W.C., Pine, D.S., \& Blair, R.J.R. (2013). Disrupted Expected Value and Prediction Error 
Signaling in Youths With Disruptive Behavior Disorders During a Passive Avoidance Task. American Journal of Psychiatry, 170(3), 315-323. https://doi.org/10.1176/appi.ajp.2012.12060840 Will, G.J., \& Klapwijk, E.T. (2014). Neural Systems Involved In Moral Judgment and Moral Action. Journal of Neuroscience, 34(32), 10459-10461. https://doi.org/10.1523/jneurosci.2005-14.2014 